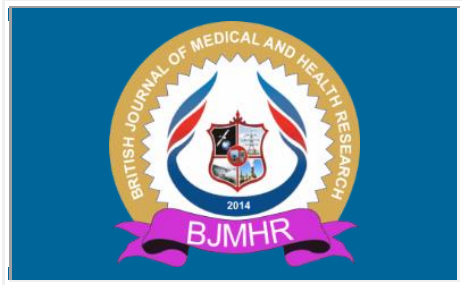

\title{
BJMHR
}

British Journal of Medical and Health Research

Journal home page: www.bjmhr.com

\section{The Effect of Cigarette Smoking on Penile Vasculature and Cardiodynamics among Young Saudi Population}

\author{
Abdulhalim S. Serafi ${ }^{1}$, Mohammed Ahmed Bafail ${ }^{1}$, Muhammad Amir Mustufa ${ }^{1}$, \\ Muhammad Irfan Safi Rizvi ${ }^{1}$, Syed Tabrez Ali $^{{ }^{*}}$ \\ 1.Department of Physiology, Faculty of Medicine, Umm-Al-Qura University, Makkah, Saudi \\ Arabia,
}

\section{ABSTRACT}

Erectile and cardiovascular dysfunctions in cigarette smokers are important signs resulting probably due to pelvic autonomic neuropathy with damage to the parasympathetic nervi erigentes. Evidence related to neuropathic etiology comes from studies that show structural changes in autonomic nerve fibers supplying the corpora cavernosa. The objective of this study was to evaluate the effect of cigarette smoking on penile mid shaft circumference and length, penile pulse amplitude, both systolic and diastolic blood pressures, and heart rate in response to erotic stimulation in young Saudi men living in Western region of Saudi Arabia (Makkah). In this free-living population study data was collected from100 men each (mild, moderate and heavy cigarette smokers) ages between 20 and 35 years with a mean age of $26.42 \pm 10.69$ years along with 100 age matched healthy non smokers who served as controls. Heavy cigarette smoker group showed a significant decrease $(\mathrm{p}<0.0005)$ in mid shaft penile circumference and length and penile pulse amplitude where as both systolic and diastolic blood pressures and heart rate exhibited a significant increase $(\mathrm{P}<0.025, \mathrm{P}<0.0005$ and $\mathrm{P}<0.005$ respectively. However this difference was found to be non significant in mild smoker group when compared with non smoker controls. We hypothesized that heavy cigarette smoking seems to be associated with sub-fertility in these males with significant alteration in the penile vasculature and cardiodynamics in a dose-dependent manner.

Keywords: Cigarette smoking, penile vasculature and cardiodynamics, young Saudi men 


\section{INTRODUCTION}

Erectile dysfunction (ED) has been found to be increasingly linked to cardiovascular risk factors and comorbidities. Since the physiological mechanism associated with erection is heavily dependent on vascular changes, most of the known cardiovascular risk factors such as hypertension and diabetes seem to be associated with the development of erectile dysfunction. It is now established that cigarette smoking is one of the most prominent factor to cardiovascular dysfunction and an independent risk factor for the development of erectile dysfunction, a more threatening form of vascular disease (1).

Several cross-sectional studies have been established now to show a correlation between cigarette smoking and ED thus exhibiting a variable baseline smoking prevalence (2). Statistically significant confidence intervals in the vast majority of these studies have been found with the odds ratio of smokers with ED ranged between 1.4 and 3.1. In a specific cohort of young men $<40$ years of age, smoking was a significant risk factor for ED. In these men, the multivariate analysis did not show significance in other vascular risk factors, strongly indicating a role for smoking in the pathogenesis of ED in younger men (3). Further analysis found that smokers who developed vascular disease had three times the risk of developing ED compared to non-smokers without vascular disease (4).

Dose dependent effects of cigarette smoking have been suggested to act as a risk-factor for heart disease as well as ED. Moreover, while reviewing the subgroup analysis from larger sample studies, a significant difference was observed in the odds ratios of patients who developed ED when smoked greater than 10 cigarettes per day (5). Among smokers, a positive but non-significant trend towards increase ED occurred in relation to daily cigarette intake (6).

In a younger, less comorbid population, heavy smokers (>20 cigarettes/day) had doubled the likelihood of severe ED compared to those who smoked less (7). Above literature thus predicts for an odds of developing ED as a result of cumulative dose of cigarette exposure suggesting that heavy smoking causes more severe ED that appears to be not reversible following smoking cessation.

Several other co-existing disorders are also known to be associated with cigarette smoking. These includes atherosclerosis and cardiovascular disease which severely affect erectile function by decreasing penile perfusion pressures resulting in increased time to maximal erection and decreased rigidity during erection (8). Cigarette smoking is associated with arteriogenic ED and is a component of the general process of atherosclerosis (9). Arterioinsufficiency also hinders erectile function by decreasing penile perfusion pressures resulting in increased times to maximal erection and decreased rigidity during erection (10). Current 
evidence suggests that there is a direct correlation between smoking and erectile dysfunctions through vascular mechanisms primarily due to depletion of nitric oxide.

Combined effects of non-optimal levels of blood pressure (BP) and smoking on cardiovascular events have been reported in epidemiological studies (11-12). A partially synergistic effect between BP and smoking status for the risk of cardiovascular disease (CVD) and stroke (predominately ischemic) has been reported in the literature (13), whereas no such relationship has also been reported. (14). Most of these studies are based on crude classifications of BP and smoking status using small database. An interaction effect between BP and smoking status for each subtype of cardiovascular disease (CVD) has also been reported, however, exact nature of this interaction (synergistic or otherwise) still remains unresolved (13).

Previous reports suggest that chronic smokers have a higher pulse rate and blood pressure compared with nonsmokers, indicating sympathetic hyperactivity (15). It has been shown that cigarette smoking acutely increases plasma catecholamines and cardiac norepinephrine spillover and results in an increase in blood pressure and heart rate and sympathetic outflow (16). However mechanisms by which smoking may affect erectile physiology are not well understood. More recent studies have reported an implication of heart rate variability (HRV) with erectile functions. Individuals with erectile impairments usually show the symptoms of abnormal cardiac autonomic regulation (sympathetic hyperactivity) while smoking cessation improve erectile functions via changes in $\operatorname{HRV}(17,18)$.

Present study has been designed to evaluate the mechanisms involved in penile hemodynamics through which cigarette smoking, as an independent risk factor induces ED. The evaluation of the differential effect of cigarette smoking on the arterial and venous components of penile vasculature and the mediating role of heart rate variability among a sample of younger aged male heavy smokers from Saudi Arabia can be used to localize the pathophysiology of vasculogenic ED in smokers, thus adding to a better understanding of this problem.

\section{MATERIALS AND METHOD}

\section{Study Design}

Present study was conducted in the Makkah Region of Saudi Arabia. Local Ethical and Protocol review committee reviewed and approved the study. Prior to the study all the subjects were provided with a written informed consent.

A total of 500 men in communities within the Makkah region, were spoken. Subjects with the history of chronic urinary tract infection, testicular injury, varicocele, disorders like diabetes, hypertension and coronary heart diseases were excluded from the study. For the experimental 
purposes 100 men each (mild, moderate and heavy smokers) ages of 20 and 35 years with a mean age of $26.42 \pm 10.69$ years along with 100 age matched non smokers healthy participant were included in the study.

Smokers were defined as subjects who were continuously smoking cigarette for at least 5 years. Smokers who smoked less than five $(<5)$ sticks of cigarette per day were classified as mild smokers, between 5 and 10 sticks of cigarette per day as moderate smokers and more than ten $(>10)$ sticks per day as heavy smokers.

Penile vasculature and cardiovascular responses were assessed using simultaneous monitoring of penile mid shaft circumference and length, penile pulse amplitude, systemic arterial systolic and diastolic blood pressures and heart rate during laboratory based erotic stimulation in all the subject groups according to the method described previously (19). The degree of erection to erotic stimulation distinguished between smoker \& non smoker etiologies. For each individual systolic and diastolic blood pressure and heart rate were measured three times with 10-15 min intervals in the sitting position and at the resting state. In most of the cases calibrated mercury sphygmomanometers were used while the use of electronic devices was kept to the minimum. The mean of each blood pressure and heart rate value was calculated by dividing the total values on the number of measurements.

\section{Statistical analysis}

Comparisons between mild, moderate and heavy smokers were performed by Student $t$ tests using SPSS program 17.0 (SPSS Institute, Inc.; Chicago, IL, USA) software. All results were tabulated as mean \pm standard deviation. In all the instances probability $(\mathrm{p}<0.05)$ was regarded as statistically significant.

\section{RESULTS AND DISCUSSION}

Data for the measurement of penile mid shaft circumference and penile length in response to film and fantasy in smoker groups (100 each) in comparison with 100 age matched nonsmokers are presented in figures- 1 and 2 respectively.

A consistent decrease in the level of penile circumference and length in the smoker groups was observed, being significant in moderate smokers $(\mathrm{p}<0.005)$, and highly significant in heavy smoker group $(\mathrm{p}<0.0005)$. However this difference was found to be non significant in mild smoker group when compared with non smoker controls.

The estimated values of penile pulse amplitude of the smoker groups and their age matched non smoker controls are presented in figure-3. Exactly in a similar manner a consistently decreased level of penile pulse amplitude was noted in almost all the smoker groups. The values of the penile pulse amplitude were found to be significant $(\mathrm{p}<0.005)$ and highly significant $(\mathrm{p}<0.0005)$ in moderate and heavy smokers respectively than their respective 
controls. However this difference was found to be non significant in mild smoker group when compared with non smoker controls.

In contrast, an inverse relationship was found when systolic and diastolic blood pressures and heart rate values were measured in the same groups. Both moderate and heavy smoker groups showed a less significant increase $(\mathrm{p}<0.025)$ in the values of systolic blood pressure (Figure 4) whereas the values of diastolic blood pressure were found to be significant $(\mathrm{p}<0.005)$ and highly significant $(\mathrm{p}<0.0005)$ in moderate and heavy smokers respectively than mild smoker group and their respective controls (Figure 5). Both moderate and heavy smokers showed a significant increase in the values of heart rate $(\mathrm{P}<0.005)$ respectively when compared with mild smokers and the respective control group.

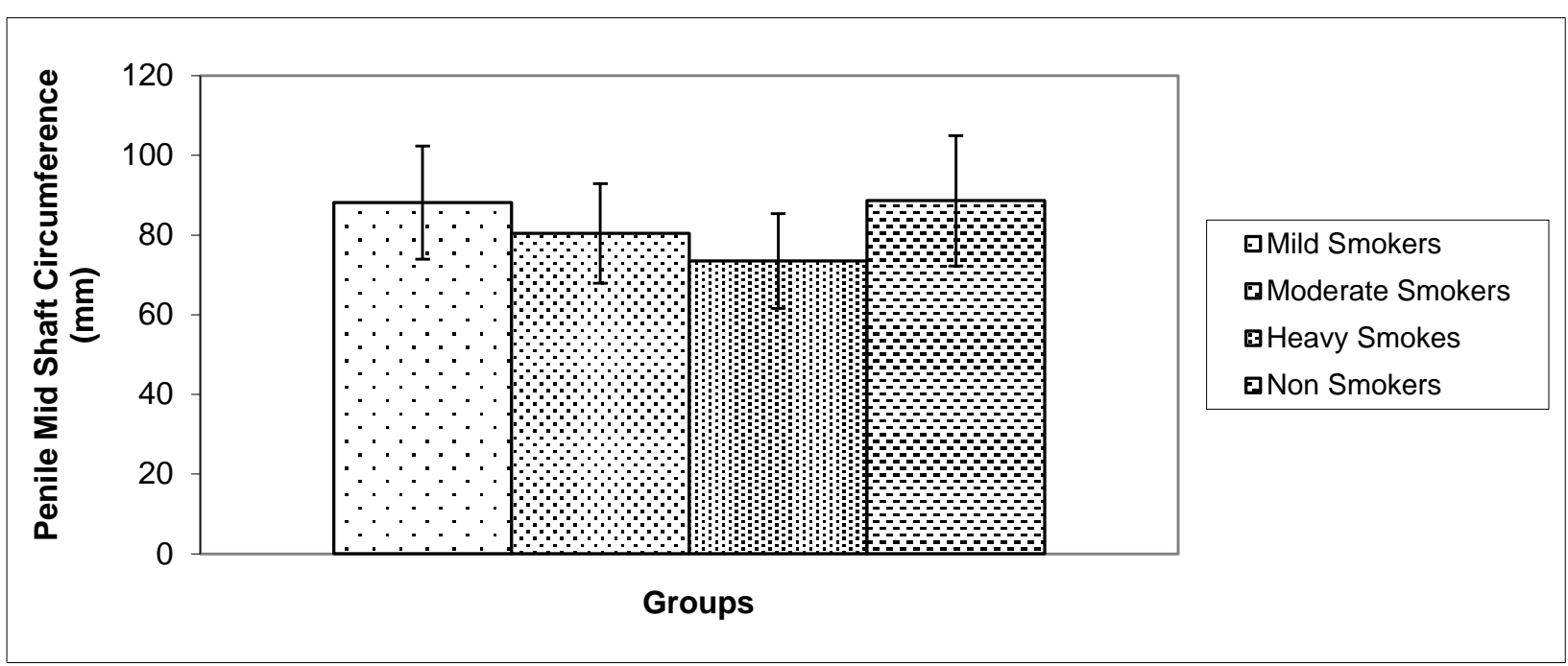

Figure 1: Changes in penile mid shaft circumference $(\mathrm{mm})$ in mild, moderate and heavy cigarette smokers compared with the age matched non smokers group in Saudi young men. Values are Mean $\pm \mathrm{SD},(\mathrm{n}=100)$. Note: $\mathrm{n}=$ Total number of subjects examined.

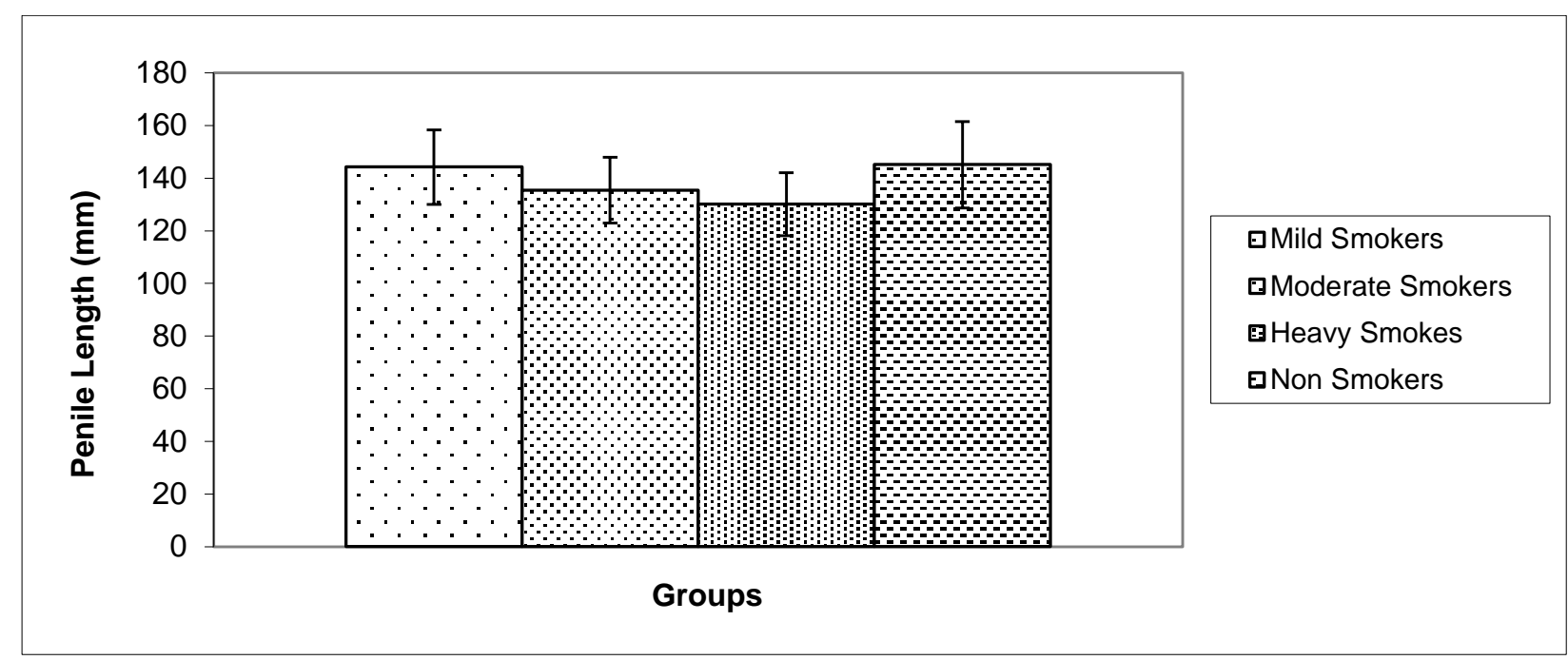

Figure 2: Changes in penile length $(\mathrm{mm})$ in mild, moderate and heavy cigarette smokers compared with the age matched non smokers group in Saudi young men.

Values are Mean $\pm \mathrm{SD},(\mathrm{n}=100)$. Note: $\mathrm{n}=$ Total number of subjects examined. 


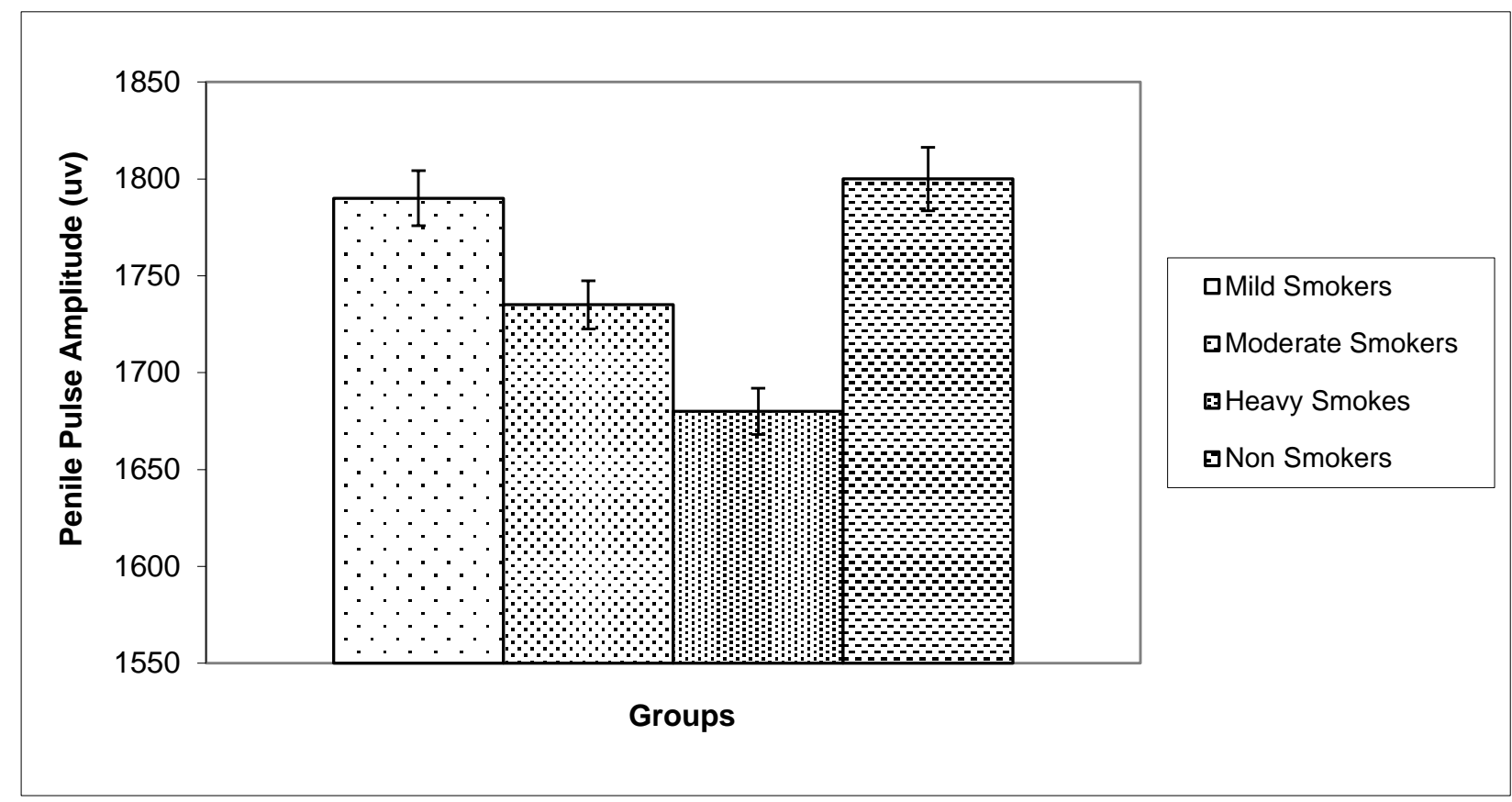

Figure 3: Changes in penile pulse amplitude $(\mu v)$ in mild, moderate and heavy cigarette smokers compared with the age matched non smokers group in Saudi young men.

Values are Mean $\pm \mathrm{SD},(\mathrm{n}=100)$. Note $: \mathrm{n}=$ Total number of subjects examined.

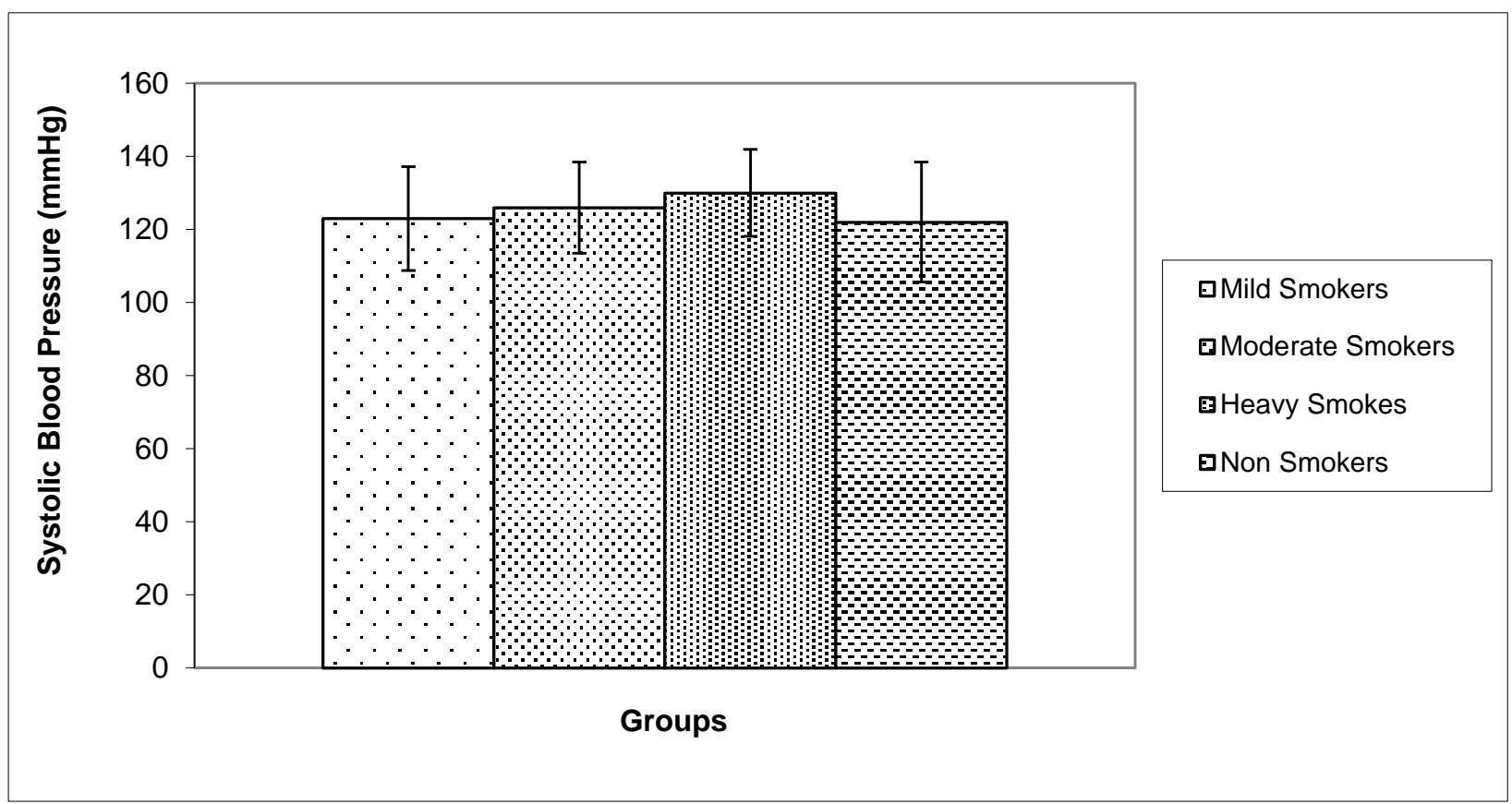

Figure 4: Changes in systolic blood pressure $(\mathrm{mmHg})$ in mild, moderate and heavy cigarette smokers compared with the age matched nonsmokers group in Saudi young men.

Values are Mean $\pm \mathrm{SD},(\mathrm{n}=100)$. Note: $\mathbf{n}=$ Total number of subjects examined. 


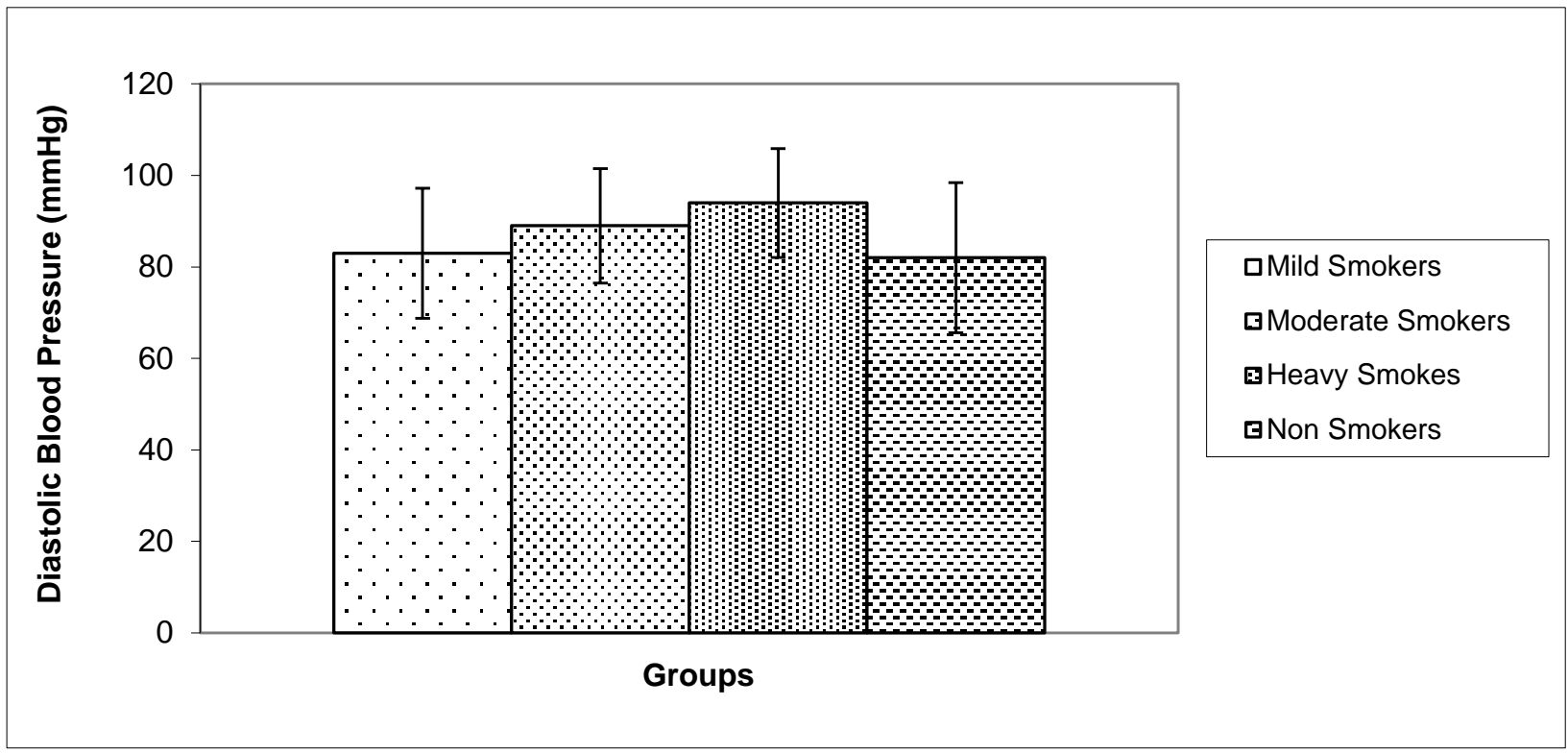

Figure 5: Changes in diastolic blood pressure (mmHg) in mild, moderate and heavy cigarette smokers compared with the age matched non smokers group in Saudi young men.

Values are Mean $\pm \mathrm{SD},(\mathrm{n}=100)$. Note: $\mathrm{n}=$ Total number of subjects examined

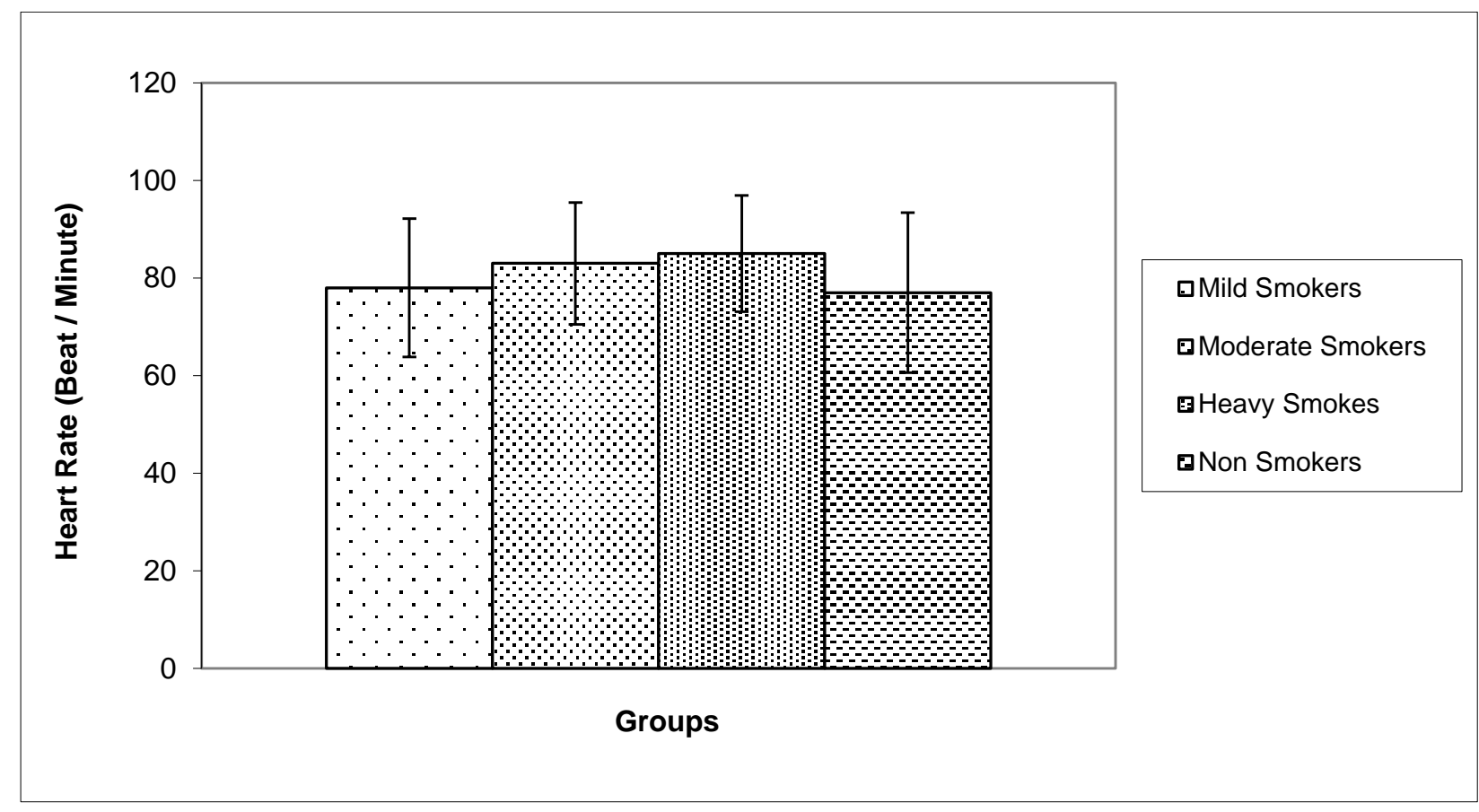

Figure 6: Changes in heart rate (beat / minute) in mild, moderate and heavy cigarette smokers compared with the age matched non smokers group in Saudi young men.

Values are Mean $\pm \mathrm{SD},(\mathrm{n}=100)$. Note: $\mathbf{n}=$ Total number of subjects examined.

\section{DISCUSSION}

Laboratory assessment of erectile response to erotic stimuli has been used for many years to assess sexual preferences as the out come of modification of deviant sexual behavior (19). In the recent years, there has been increasing recognition that many cases of erectile dysfunctions are due, at least in part, to physical factors. Evidence indicates that erection may 
involve the activation of several separate mechanisms (20). In addition to parasympathatically mediated arterial vasodilatation, there may also be active reduction of venous drainage (21) and the active closure of intra cavernosal arterio-venous shunts (22). Studies have suggested that tobacco- induced ED is mainly a result of vasculogenic etiology and is an independent risk factor in the development of atherosclerotic lesions in the internal pudendal and common penile arteries of young impotent men (23). Indirect evidences further suggest that smoking affects penile erection by impairment of endothelium-dependent smooth muscle relaxation (24). Our results indicated that during the period of erotic stimulation penile mid shaft circumference, penile length, and penile pulse amplitude exhibited a highly significant decrease $(\mathrm{P}<0.0005)$ in heavy smoker group, however this difference was found to be less significant in moderate smoker group $(\mathrm{P}<0.005)$ and non-significant in mild smoker group when compared with their respective nonsmoker control group. These results are in agreement with previous findings where penile rigidity during nocturnal erections was inversely correlated with the number of cigarettes smoked per day (25).

Numerous previous studies have indicated that ED in smokers is mainly due to underlying vascular pathology and an independent risk factor in the development of atherosclerotic lesions in the internal pudendal and common penile arteries of young impotent men (23). We found an increase in the values of systolic and diastolic blood pressures and heart rate in both heavy and moderate smoker groups where as this difference was found to be non significant in mild smoker group when compared with their respective control subjects.

Although several studies have been published in the recent years on this topic, however, there is no firm consensus on the relationship between smoking and blood pressure and heart rate and this issue still remains controversial due to multiple confounding factors (26), since the precise effect of smoking habits on blood pressure and heart rate is unclear. Some investigators demonstrated that there were no association between smoking habits and blood pressure values (27). However, other investigators confirmed that smokers had either lower (28) or higher (29) blood pressure values than non-smokers. Furthermore, some studies confirmed the presence of a significant dose-effect correlation between the number of cigarettes smoked per day and the alteration of blood pressure (28). Furthermore in epidemiologic investigation, smokers have higher blood pressure and heart rate than nonsmokers (26). These results are in agreement with our findings as well as other investigations (29). This increase may be attributed to the activation of nicotinic receptors of the sympathetic ganglia leading to increase in norepinephrine release and elevation of blood pressure. The dose-effect correlation of smoking on heart rate was positive and significant in our studies. This may be interpreted as an effect of the nicotine of cigarettes which enhances local and systemic catecholamine release, and may also stimulate vasopressin release by 
acting as an adrenergic agonist. Our results are thus in conformity with the previous findings (30). In agreement with our results, a prompt increase in heart rate and blood pressure has been observed during the first 5 minutes after smoking (31). The mechanism of acute smoking-induced changes in heart rate variability is probably complex; however, most of the acute effects of smoking on neuro-cardiovascular regulation have been mainly attributed to nicotine, which is the main constituent of cigarette. Nicotine is known to exert both acute and chronic cardiovascular effects, mainly through sympathetic activation as a consequence of enhanced release of catecholamine. Indeed, nicotine is implicated in a wide spectrum of cardiac rhythm disorders, including transient sinus arrest and/or bradycardia, sinus tachycardia, atrial fibrillation, sinoatrial block, atrio-ventricular block, and ventricular tachyarrhythmias, therefore, nicotine may in part be associated with the changes in heart rate variability as observed after smoking a cigarette (32).

\section{CONCLUSION}

On the basis of our findings, we concluded that cigarette smoking has a significant adverse reproductive outcome in younger aged Saudi men probably due to impaired penile venoocclusive mechanisms. These changes seem to be associated with cardiac adverse events attributed to smoking. These findings might serve to guide further studies investigating the pathophysiological basis of penile hemodynamics in smoking males.

\section{REFERENCES}

1. Miner M, Seftel AD, Nehra A, Ganz P, Kloner RA, Montorsi P, Vlachopoulos C, Ramsey M, Sigman M, Tilkemeier P, Jackson G. Prognostic utility of erectile dysfunction for cardiovascular disease in younger men and those with diabetes. Am Heart J. 2012; 164:21-28.

2. Wu C, Zhang H, Gao Y, Tan A, Yang X, Lu Z, Zhang Y, Liao M, Wang M, Mo Z. The association of smoking and erectile dysfunction: results from the Fangchenggang Area Male Health and Examination Survey. (FAMHES) J Androl. 2012; 33:59-65.

3. Elbendary MA, El-Gamal OM, Salem KA. Analysis of risk factors for organic erectile dysfunction in Egyptian patients under the age of 40 years. J Androl. 2009; 30:520524.

4. Shiri R, Hakkinen J, Koskimaki J, Tammela TL, Auvinen A, Hakama M. Smoking causes erectile dysfunction through vascular disease. Urology. 2006; 68:1318-1322.

5. Austoni EMV, Parazzini F, Fasolo CB, Turchi P, Pescatori ES, Ricci E, Gentile V. Andrology Prevention Week centres; Italian Society of Andrology. Eur Urol. 2005; 48:810-818. 
6. Chew KK, Bremner A, Stuckey B, Earle C, Jamrozik K. Is the relationship between cigarette smoking and male erectile dysfunction independent of cardiovascular disease? Findings from a population-based cross-sectional study. J Sex Med. 2009; 6:222-231.

7. Natali A, Mondaini N, Lombardi G, Del Popolo G, Rizzo M. Heavy smoking is an important risk factor for erectile dysfunction in young men. Int J Impot Res. 2005; 17:227-230.

8. Shabsigh R, Fishman IJ, chum C, Dunn JK. Cigarette smoking and other vascular risk factors in vasculogenic impotence. Urology. 1991; 38:227-231.

9. Sullivan ME, Thompson CS, Dashwood MR, Khan MA, Jeremy JY, Morgan RJ, Mikhailidis DP. Nitric oxide and penile erection: is erectile dysfunction another manifestation of vascular disease? Cardiovasc Res. 1999; 43:658-665.

10. Dean RC, Lue TF. Physiology of penile erection and pathophysiology of erectile dysfunction. Urol Clin North America. 2005; 32:379-395.

11. Yamagishi K, Iso H, Kitamura A, Sankai T, Tanigawa T, Naito Y, Sato S, Imano H, Ohira T, Shimamoto T. Smoking raises the risk of total and ischemic strokes in hypertensive men. Hypertens Res. 2003; 26: 209-217.

12. Khalili P, Nilsson PM, Nilsson JA, Berglund G. Smoking as a modifier of the blood pressure-induced risk of cardiovascular events and mortality: a population-based prospective study of middle-aged men. J Hypertens. 2002; 20: 1759-1764.

13. Kiyohara Y, Ueda K, Fujishima M. Smoking and cardiovascular disease in the general population in Japan. J Hypertens. 1990; 8 (Suppl 5): S9-S15.

14. Wolf PA, D’Agostino RB, Kannel WB, Bonita R, Belanger AJ. Cigarette smoking as a risk factor for stroke. The Framingham Study. JAMA. 1988; 259: 1025-1029.

15. Gidding SS, Xie X, Lui K, et al: Cardiac function in smokers and nonsmokers: The CARDIA study. J Am Coll Cardiol. 1995; 26:211-216. , 1995.

16. Narkiewicz K, van de Borne PJ, Hausberg M, et al: Cigarette smoking increases sympathetic outflow in humans. Circulation. 1998; 98:528-534.

17. Chen CJ, Kuo TBJ, Tseng YJ, Yang CCH. Combined cardiac sympathetic excitation and vagal impairment in patients with non-organic erectile dysfunction. Clin Neurophysiol. 2009; 120(2):348-352.

18. José J M, Juan F, Evalinda BV, Ana LSO, Ben MW, Timo S.Autonomic Dysfunction in $\alpha$-Synucleinopathies. Front Neurol. 2019; 10: 363.

19. Bancroft J, Bell C. Simultaneous recording of penile diameter and penile arterial pulse during laboratory based erotic stimulation in normal subjects. J Psychom Med. 1985; 29:303-13. 
20. Braunstein GD. Impotence in diabetic men. Mt Sinai J Med 1987; 54:236-40.

21. Wagner G. Vascular mechanisms involved in erection and erectile disorders. Clinics In Endocrinol Metab 1982; 11:717.

22. Sommer F, Klotz T, Engelmann U. Improved spontaneous erectile function in man with mild to moderate arteriogenic erectile dysfunction treated with a nightly dose of Sildenafil for one year: a randomized trail. Asian J Androl 2007; 9(1):134-41.

23. Rosen M, Greenfield A, Walker T, Grant P, Dubrow J, Bettman M, Fried L, Goldstein Cigarette smoking: an independent risk factor for atherosclerosis in the hypogastriccavernous arterial bed of men with arteriogenic impotence. J Urol. 1991; 145: 759763.

24. Giuseppe S, Alberto C, Daniela B, Michela B, Gaetano C, Linda C, Eugenio M. Anatomy, Pathophysiology, Molecular Mechanisms, and Clinical Management of Erectile Dysfunction in Patients Affected by Coronary Artery Disease: A Review. Biomedicines. 2021; 9 (4): 432.

25. Xie Y, Garban H, Ng C, Rajfer J, Gonzalez-Cadavid NF. Effect of long term passive smoking on erectile dysfunction and penile nitric oxide synthetase. $\mathbf{J}$ Urol. 1997; 157: 1121- 1126.

26. Lee DH, Ha MH, Kim JR, et al. Effects of smoking cessation on changes in blood pressure and incidence of hypertension: a 4-year follow-up study. Hypertension. 2001; 37: 194-8.

27. Primatesta P, Falaschetti E, Gupta S, Marmot MG, Poulter NR. Association between smoking and blood pressure. Evidence from the health survey for England. Hypertension. 2001; 37: 187 - 93.

28. Imamura H, Tanaka K, Hirae C, Futagami T, Yoshimura Y, Uchida K, et al. Relationship of cigarette smoking to blood pressure and serum lipids and lipoproteins in men. Clin Exp Pharmacol Physiol. 1996; 23: 397 - 402.

29. Elliott JM, Simpson FO. Cigarettes and accelerated hypertension. NZ Med J. 1980; 91: $447-9$.

30. Cryer PE, Haymond MW, Santiago JV, Shah SD. Norepinephrine and epinephrine release and adrenergic mediation of smoking associated hemodynamic and metabolic events. New Engl J Med. 1976; 295:573 - 7

31. Stefanadis C, Tsiamis E, Vlachopoulus C, et al: Unfavorable effect of smoking on the elastic properties of the human aorta. Circulation. 1997; 95:31-38.

32. Sara A, Kacey P, Yasmine C, Roya M, Kevin N, Elizabeth T, Jeffrey G, Holly R. Acute and chronic sympathomimetic effects of e-cigarette and tobacco cigarette smoking: role of nicotine and non-nicotine constituents. Environmental Inhalants and 
Cardiovascular Disease. Am J Physiol Heart Circ Physiol. 2020; 319 (2): H262H270.

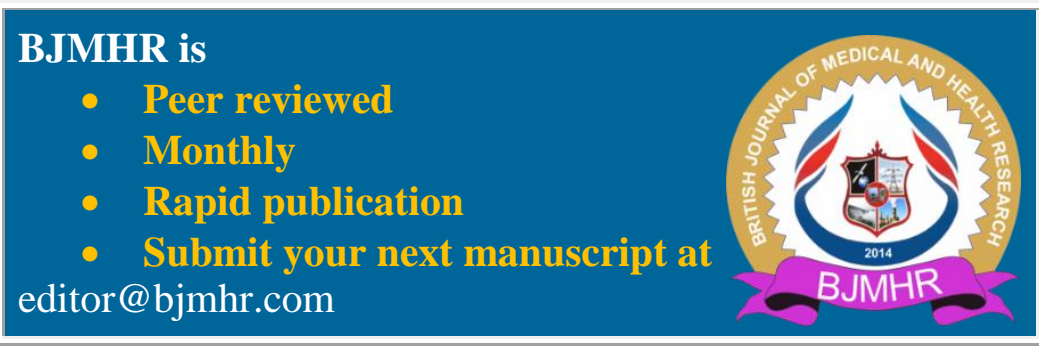

